\title{
Effects of prior knowledge and concept-map structure on disorientation, cognitive load, and learning
}

Citation for published version (APA):

Amadieu, F., Van Gog, T., Paas, F., Tricot, A., \& Mariné, C. (2009). Effects of prior knowledge and concept-map structure on disorientation, cognitive load, and learning. Learning and Instruction, 19(5), 376-386.

https://doi.org/10.1016/j.learninstruc.2009.02.005

DOI:

10.1016/j.learninstruc.2009.02.005

Document status and date:

Published: 01/10/2009

Document Version:

Early version, also known as pre-print

Please check the document version of this publication:

- A submitted manuscript is the version of the article upon submission and before peer-review. There can be important differences between the submitted version and the official published version of record. People interested in the research are advised to contact the author for the final version of the publication, or visit the DOI to the publisher's website.

- The final author version and the galley proof are versions of the publication after peer review.

- The final published version features the final layout of the paper including the volume, issue and page numbers.

Link to publication

\section{General rights}

Copyright and moral rights for the publications made accessible in the public portal are retained by the authors and/or other copyright owners and it is a condition of accessing publications that users recognise and abide by the legal requirements associated with these rights.

- Users may download and print one copy of any publication from the public portal for the purpose of private study or research.

- You may not further distribute the material or use it for any profit-making activity or commercial gain

- You may freely distribute the URL identifying the publication in the public portal.

If the publication is distributed under the terms of Article 25fa of the Dutch Copyright Act, indicated by the "Taverne" license above, please follow below link for the End User Agreement:

https://www.ou.nl/taverne-agreement

Take down policy

If you believe that this document breaches copyright please contact us at:

pure-support@ou.nl

providing details and we will investigate your claim.

Downloaded from https://research.ou.nl/ on date: 26 Apr. 2023 
Running Head: Prior knowledge and concept-map structure

This is a pre-print of:

Amadieu, F., Van Gog, T., Paas, F., Tricot, A., \& Mariné, C. (2009). Effects of prior knowledge and concept-map structure on disorientation, cognitive load, and learning. Learning and Instruction, 19, 376-386.

Copyright Elsevier, available online at http://www.elsevier.com/wps/find/journaldescription.cws_home/956/description\# description

Effects of prior knowledge and concept-map structure on disorientation, cognitive load, and learning

Franck Amadieu ${ }^{\mathrm{a}, *}$, Tamara van Gog ${ }^{\mathrm{b}}$, Fred Paas ${ }^{\mathrm{b}, \mathrm{c}}$, André Tricot ${ }^{\mathrm{a}}$, Claudette Mariné

${ }^{\text {a }}$ Cognition, Tongues, Language, Ergonomics - Work and Cognition Laboratory, University of Toulouse, France

${ }^{\mathrm{b}}$ Centre for Learning Sciences and Technologies, Open University of the Netherlands ${ }^{\mathrm{c}}$ Psychology Department, Erasmus University Rotterdam, The Netherlands

Author Note

* Correspondence should be addressed to Franck Amadieu, Cognition, Tongues, Language, Ergonomics - Work and Cognition Laboratory, University of 
Prior Knowledge and Concept-map Structure 2

Toulouse le Mirail, 5 allées Antonio Machado, F-31058 Toulouse Cedex 9, France.

Tel.: +33 561 503526; fax: +33 561 503533; E-mail: $\underline{\text { amadieu@univ-tlse2.fr }}$ 


\begin{abstract}
This study explored the effects of prior knowledge (high vs. low; HPK and LPK) and concept-map structure (hierarchical vs. network; HS and NS) on disorientation, cognitive load, and learning from non-linear documents on "the infection process of a retrograde virus (HIV)". Participants in the study were 24 adults. Overall subjective ratings of disorientation and cognitive load, as well as detailed analysis of eye movement and navigation data were used. The results showed that LPK learners gained equal factual knowledge from the HS and NS concept maps, gained more conceptual knowledge from the HS concept map, and had to invest less mental effort in the posttest after learning with the HS concept map. On the other hand, HPK learners gained more factual knowledge from the HS concept map than from the NS concept-map, and gained equal conceptual knowledge from both concept-map structures. Also, LPK learners experienced higher disorientation during learning with the NS concept-map than the HS map, whereas no differential effect of concept-map structure was found for HPK learners. Both LPK and HPK learners invested less mental effort in processing the HS concept map. The eye tracking and navigation data provided more detailed insight into these findings.
\end{abstract}

Key words: Cognitive load; Concept map; Expertise Reversal Effect; Non-linear Document; Prior Knowledge 


\section{Introduction}

Learning from hypertext has been an active area of research for two decades. Hypertexts are non-linear electronic documents that provide a flexible structure for dynamic exploration of information where the nodes (textual chunks) and links between the nodes provide a structure of the semantic space (Conklin, 1987; Dillon, Mc Knight, \& Richardson, 1993). In other words, the non-linear structure of hypertexts allows, but also requires the user to determine his/her own sequence of reading information, which, arguably, has important consequences for disorientation and cognitive load, especially for low prior knowledge learners. Disorientation is defined as a psychological state resulting from problems in constructing the pathways across a hypertext (Conklin, 1987) and in constructing a mental representation of the physical and conceptual space of hypertexts (Cress \& Knabel, 2003).

However, even though hypertexts are non-linear, hypertext structures providing organisational links and organisational cues (e.g., a hierarchical structure) can be considered somewhat more "linear" (or logical) than structures which provide different types of relational links (e.g., network structures). The present study investigates the effects of prior knowledge and of two types of concept-map structures (i.e., hierarchical and network), on disorientation, cognitive load, and learning. Particular attention was given to techniques for detailed analysis of learning processes that occur in response to the different types of concept maps at different levels of prior knowledge, using eye movement data and navigation data.

\subsection{Effects of structure and prior knowledge on learning from hypertexts}

To learn from hypertext (i.e., to construct a schema or mental model of the content of the hypertext) learners need to process information within a node (piece of information) and to understand the relations between nodes. Hypertexts have been 
argued to support learning because: (a) they are organized in a way that is similar to the knowledge structure in memory (i.e., associative network), which would facilitate the processes of accessing and integrating information (Fiderio, 1988; Jonassen, 1989), and (b) they are fitted to all learner profiles because their structure is flexible and therefore adaptive to individual learners' needs. However, several studies that sought to establish the positive effect of structure flexibility failed to corroborate the postulates (Jacobson \& Archodidou, 2000; Jacobson, Maouri, Mishra, \& Kolar, 1996). A possible explanation for this failure to find positive effects is that hypertexts do not just allow learners to flexibly determine their own path, but require them to do so. The expectation that flexible exploration in hypertexts leads to better learning is based on the implicit assumption that learners are able to determine which information they wish to explore and to keep in mind previously explored information to which they can relate the new information. However, selecting information, processing it, and integrating it with previously selected information imposes high demands on learners' cognitive resources and may lead to disorientation and cognitive overload, which can negatively affect performance (Ahuja \& Webster, 2001; Otter \& Johnson, 2000).

Two factors presumably influence the effectiveness of hypertext learning: (a) the degree of guidance provided, for example by the structure of a concept map, and (b) the prior knowledge of the learner (Chen \& Rada, 1996; Dillon \& Gabbard, 1998; Shapiro \& Niederhauser, 2004; Shlechter, 1993). The structure of a concept map is defined by the number of nodes and the relations between the nodes (e.g., organisational as in hierarchical concept maps vs. relational as in network concept maps; Mohageg, 1992). Hierarchical concept maps provide a high degree of structure and can facilitate learners' orientation in the organization of the material, thereby 
facilitating navigation and reducing the cognitive load associated with navigating through the hypertext. This would lead to lower cognitive load. (For Cognitive Load Theory see Sweller, 1988; Sweller, van Merriënboer, \& Paas, 1998.) On the contrary, concept maps that have low degree of structure or structure that is not directly obvious to the learners (e.g., network maps) provide little guidance and make navigation difficult, thus increasing disorientation and cognitive load. Learners' prior knowledge is important because it allows coping with the cognitive demands imposed by hypertext learning since learners can use their own mental representation of the knowledge domain to guide their navigation and the processing of the content of the concept map.

The level of prior knowledge is presumably a strong moderator of the relationship between the degree of the structure of the concept map and the learning outcomes. Findings on the expertise reversal effect (Kalyuga, Ayres, Chandler, \& Sweller, 2003; Seufert, 2003; Van Gog, Paas, \& Van Merriënboer, 2008) suggest that for high prior knowledge learners, high levels of guidance provided by the conceptmap structure may no longer contribute to learning, or even hamper learning (see also Chen, Fan, \& Macredie, 2006). The expertise reversal effect is an example of an Aptitude-Treatment-Interaction effect (ATI; Cronbach \& Snow, 1977), although studies on ATI focused on aptitudes rather than prior knowledge or expertise (e.g., Seufert, Schützea, \& Brünkena, in press). Studies on ATI also indicated that optimal learning depends on whether the format of instruction matches with the aptitudes of the learner: low control of the task by the learner and structured treatments would help learners with low ability whereas they would hinder those with high abilities (see, e.g., Lohman, 1986; Snow, 1989). 
Hypertext studies have shown that the use of different types of document structure does not seem to affect performance for high prior knowledge learners (Amadieu, Tricot, \& Mariné, in press; Calisir \& Gurel, 2003; Patel, Drury, \& Shalin, 1998; Potelle \& Rouet, 2003), whereas for low prior knowledge learners the representation of a well-organised structure may support deep comprehension (de Jong \& van der Hulst, 2002; Shapiro, 1999) and the construction of a macro-structural text representation (Potelle \& Rouet, 2003). Other evidence corroborating the expertise reversal effect comes from the closely related field of text comprehension. Studies have shown an impact of text coherence on learning depending on prior knowledge (McNamara \& Kintsch, 1996; McNamara, Kintsch, Songer, \& Kintsch, 1996; Ozuru, Dempsey, \& McNamara, in press). High coherence, which presumably provides more structure to the reader, was found to lead to better text-based recall than low coherence, for both high and low prior knowledge learners. However, whereas low prior knowledge learners constructed a better situation model (as assessed by inference questions and problem-solving questions) from high coherence text, high prior knowledge learners were able to construct a more elaborate situation model from low-coherence text (McNamara et al., 1996). In hypertext research, similar results were found by Salmeron, Cañas, Kintsch, and Fajardo (2005). Their findings indicated that high prior knowledge learners benefited more from low coherence pathways (referential coherence) across a hierarchical hypertext whereas low prior knowledge learners benefited more from coherent pathways (better situation model). Therefore, low in coherence reading sequences may support deep processing for high but not for low prior knowledge learners.

Given that results on the beneficial effects of hypertext learning have been inconclusive, although there are strong indications that these are moderated by prior 
knowledge and level of guidance provided by the structure of the hypertext, more research on the relationship between prior knowledge, navigational behaviours, disorientation, and resulting learning outcomes is necessary (Shapiro \& Niederhauser, 2004). In doing so, it is important to measure disorientation and cognitive load directly, instead of using it as a post-hoc explanation that is not supported by data as many studies tend to do (Scott \& Schwartz, 2007), and to analyze the learning process on a more detailed level, such as eye movements, which may contribute to a better understanding of how prior knowledge and concept-map structure affect learning.

\subsection{Measuring cognitive load with subjective ratings and eye tracking}

Cognitive load can be measured with subjective and objective techniques (see Paas, Tuovinen, Tabbers, \& Van Gerven, 2003). An often-used subjective technique is the 9-point mental effort rating scale developed by Paas (1992). Investment of mental effort is considered to reflect the actual cognitive load allocated to task performance, and the mental effort rating scale is easy to use (non-intrusive) and provides a good indication of overall cognitive load (Paas et al., 2003).

An objective technique that is very suited for studying cognitive processes and processing demands (i.e., cognitive load) is eye tracking (Duchowski, 2003; Rayner, 1998). Eye fixation data reflect attention and shifts in attention, which are partly influenced by prior knowledge: Exogenous shifts occur mainly in response to environmental features/changes in the environment (e.g., if something brightly coloured would start flashing in the corner of your computer screen while you are working, your attention will be drawn to it), but endogenous shifts are driven by knowledge of the task, of the environment, and of the importance of available information sources (Stelmach, Campsall, \& Herdman, 1997; Underwood, Chapman, Brocklehurst, Underwood, \& Crundall, 2003). It has been shown that with increasing 
knowledge or expertise individuals learn to fixate more on task-relevant information, which has been shown for experts compared to novices (Charness, Reingold, Pomplun, \& Stampe, 2001; Haider \& Frensch, 1999), and seems to occur with smaller differences in expertise levels as well (Van Gog, Paas, \& Van Merriënboer, 2005).

Moreover, eye movement data can provide information about the cognitive load imposed by particular cognitive processes. For example, pupil dilation (Beatty, 1982; Van Gerven, Paas, Van Merriënboer, \& Schmidt, 2004), and fixation duration (Underwood, Jebbett, \& Roberts, 2004) are known to increase with increased processing demands (task difficulty), whereas the length of saccades decreases (for an in-depth discussion of eye movement data and cognitive processes, see Rayner, 1998). So, in studies such as the present one, eye tracking can provide interesting information about different navigation/orientation processes, as well as the processing demands imposed by those processes. For instance, Naumann, Waniek, and Krems (2001) showed that a linear hypertext structure yielded better comprehension performance than a non-linear structure for novices, which was presumably caused by longer fixation time on the text in the linear structure. That is, the additional task of navigation in the non-linear structure seems to have drawn attentional resources away from the text, thereby hampering comprehension. Eye movement data provide direct and detailed measures of attention and processing demands, whereas subjective measures, such as self-ratings, are overall measures of experienced processing demands (e.g., mental effort and disorientation); thus, collecting data of both types is expected to have added value and contribute to our understanding of the effects of concept-map structure and prior knowledge on learning with non-linear documents. 


\subsection{The present study - Hypotheses}

The aim of the present study was, first, to explore the effects of prior knowledge and concept-map structure on disorientation, cognitive load, and learning from hypertext and, second, to explore the added value of combining different process measures, that is, using overall subjective ratings of disorientation and cognitive load as well as more detailed measures such as eye movement and navigation data.

Two types of concept-map structure (see Figure 1) were implemented: a hierarchical structure (HS) and a network structure (NS). The hierarchical structure as compared to the network structure was expected to guide learners' attention towards the main concepts and their semantic relationships (concepts belonging to the same topic) (Hypothesis 1a), and to guide their navigation path in a coherent way such as topic coherence or temporal-causal coherence (Hypothesis 1b).

An expertise reversal effect was also hypothesized. For low prior knowledge learners, the hierarchical structure, as compared to the network structure, would facilitate orientation in the organization of the nodes and, thus reduce disorientation (Hypothesis 2a) and the cognitive load (Hypothesis 2b). Moreover, mean duration of eye fixations during concept-map processing in the network structure was expected to be longer for low prior knowledge learners, as compared to the hierarchical structure, reflecting the higher processing demands (cognitive load) and disorientation imposed by this type of concept map (Hypothesis 2c). Therefore, the hierarchical structure would improve learning performance more than the network structure for low prior knowledge learners (Hypothesis 2d).

The high prior knowledge learners, on the other hand, by having at their disposal mental models, they would be able to cope with the lower degree of structure provided by the network structure, without getting disoriented (Hypothesis 3a) or 
experiencing high levels of cognitive load (Hypothesis 3b). Thus, no difference in mean duration of eye fixations (Hypothesis 3c) and in learning performance (Hypothesis 3d) was expected between the two types of structure for high prior knowledge learners.

\section{Method}

\subsection{Design - Participants}

A 2 × 2 factorial design was used with the factors Concept-Map Structure (HS vs. NS) and Prior Knowledge (low vs. high), resulting in four conditions: Network Structure and Low Prior Knowledge (NS/LPK), Network Structure and High Prior Knowledge (NS/HPK), Hierarchical Structure and Low Prior Knowledge (HS/LPK), and Hierarchical Structure and High Prior Knowledge (HS/HPK).

Twenty-four employees (research, teaching, and support staff) of a Dutch university volunteered to participate in this experiment (age $\underline{\mathrm{M}}=32.3, \underline{\mathrm{SD}}=8.05 ; 15$ females and 9 males). The distribution of age across the conditions was quite equal $(\mathrm{HS} / \mathrm{LPK}: \underline{\mathrm{M}}=31.00, \underline{\mathrm{SD}}=7.29 ; \mathrm{NS} / \mathrm{LPK}: \underline{\mathrm{M}}=34.83, \underline{\mathrm{SD}}=9.97 ; \mathrm{HS} / \mathrm{HPK}: \underline{\mathrm{M}}=$ 31.83, $\underline{\mathrm{SD}}=7.25 ; \mathrm{NS} / \mathrm{HPK}: \underline{\mathrm{M}}=31.67$; $\underline{\mathrm{SD}}=9.09$ ). In three of the conditions there were three males and three females, whereas in one condition all participants were female (NS/LPK). All participants used computers and Internet daily.

\subsection{Material}

\subsubsection{Learning task}

The Learning task was created (in collaboration with an assistant professor of biology) in Microsoft Powerpoint and was delivered in Microsoft Internet Explorer. It consisted of 25 short texts/nodes (in Dutch) about the infection process of the retrograde virus HIV (human immune deficiency virus). The total length of the text was 1202 words. One text/node dealt with introductory information about HIV, 
eleven dealt with anatomic information (i.e., constitutive elements of the host cell and the virus), and thirteen dealt with functional information (i.e., events in the multiplication process). Concept labels and text sections were equivalent between the two structure conditions. See Figure 1 for the screens displaying the two concept maps.

Insert Figures $1 \mathrm{a}$ and $1 \mathrm{~b}$ about here

The short texts could be accessed by clicking on nodes in the concept map, which displayed the concept name. To exit a text/node, a back button had to be clicked to return to the concept map (no other hyperlinks were present in the text). The concept map was either of HS or NS (see Figures 1a and 1b). The two conceptmap structures differed in the type of links between nodes (see Mohageg, 1992): In the HS, links were organisational, communicating sub-/superordinate relations of concepts (horizontal organization) as well as sequence of events (vertical organisation); in the NS, links were relational (i.e., they displayed relations such as belongs to, follows, causes, shares elements, but the links were not labelled as such), communicating a spatial organisation of concepts and sequence of events and avoiding thematic aggregations.

\subsubsection{Training task}

The Training task contained information on a similar cell infection process as presented in the Learning task, but was about a different retrograde virus (the equine infectious anemia virus - EIAV), and was presented linearly and on paper (one page A4). The steps of the virus multiplication cycle were exactly similar as those of HIV (i.e., the Learning task). 


\subsection{Measures}

\subsubsection{Prior Knowledge test}

Prior domain knowledge of cell biology was assessed with ten multiple-choice questions with five answer options for each one: one of the option answers was "I do not know" to avoid random answering. The maximum score was 10 points. The questions dealt with general factual knowledge about elements of a human cell (e.g., the nature of genetic information, the main function of enzymes, or the function of mitochondria). No specific topic knowledge of viruses was assessed because prior knowledge of retro-virus infectiousness process was assessed by the pretest (see below). The internal consistency (Cronbach's alpha) of the prior knowledge set of questions was .85 .

The Prior Knowledge test was administered a few days prior to the experimental session and was used to assign participants to the LPK or HPK conditions. This was done based on a median split (the median was 3). The LPK conditions had a mean score of $1.83(\underline{\mathrm{SD}}=0.94)$ and the HPK conditions had a mean score of $6.17(\underline{\mathrm{SD}}=2.25)$. By applying the Mann-Whitney $\mathrm{U}$ test, this difference was found significant, $\underline{\mathrm{U}}(12,12)=2, \underline{\mathrm{p}}<.001$. Participants in the LPK and HPK conditions were randomly assigned to the NS and HS conditions (i.e., $\underline{\mathrm{n}}=6$ per condition). No significant difference was observed between the two types of conceptmap structure for LPK participants, $\underline{\mathrm{U}}(6,6)=15$, $\underline{\mathrm{ns}}$, and for the HPK participants, $\underline{\mathrm{U}}(6,6)=17.5, \underline{\mathrm{ns}}$.

\subsubsection{Pre- and posttest}

Learning performance was assessed with a pre- and posttest. The pre- and the posttest were the same and consisted of a statement judging task. Participants were presented with thirty-two statements about the HIV cycle and had to answer if each 
statement was right (true) or wrong (false). The posttest statements were exactly similar to the pretest statements but were offered in reverse order (for example statements, see Appendix A).

The statements were delivered one by one on the computer screen with Inquisit 2.0.51002 software (Millisecond Software LLC, 2005). Participants were instructed to respond "right", "wrong", or "I do not know" (included to avoid random answers) by pressing the P key (upper right corner), the Q key (upper left corner), or spacebar (low middle), respectively. The first set of 16 statements (presented in the same order for all participants) assessed factual knowledge. Answering these statements correctly required factual knowledge, that is, information presented explicitly and in a single node in the Learning task. The second set of 16 statements (presented in the same order for all participants) assessed conceptual knowledge. Answering these statements correctly required a combination of information presented in at least two, and up to 3 , different nodes in the Learning task. To answer these statements correctly learners needed a coherent mental model of the virus, the human cell, and the multiplication cycle (or parts of the cycle). Each correct answer was scored by one point.

The internal consistency (Cronbach's alpha) of the factual knowledge set of questions was .59, and of the conceptual knowledge set was .62.

\subsubsection{Cognitive load and disorientation measures}

Cognitive load was measured with self-ratings of mental effort developed by Paas (1992). Two mental effort items were associated with the Learning task: One general item ("Please indicate how much mental effort you invested in studying the Learning task") and one specific item ("Please indicate how much mental effort you invested to understand the concept map"). The general item was also used for the 
posttest: "Please indicate how much mental effort you invested in answering the test questions". The response scale to each item ranged from 1 (very very low) to 9 (very very high").

Disorientation was measured using a Disorientation Scale consisting of five items based on the work of Ahuja and Webster (2001). The items were modified to fit our material and regarded (a) the difficulty to understand the relations between nodes, (b) to know what next node to consult, (c) to know one's state in the lesson, (d) to find information, and (e) to be on the right path (see Appendix B). The response scale to each item ranged from 1 (very very low) to 9 (very very high"). The Disorientation Scale showed a high internal consistency (Cronbach's alpha $=.91)$.

\subsubsection{Time on Learning task}

The time spent on the Learning task was logged.

\subsubsection{Time on posttest}

The time spent on the posttest was also logged.

\subsection{Instruments}

\subsubsection{Eye-tracking hardware and software}

A $50 \mathrm{~Hz}$ video-based remote eye-tracking device from SensoMotoric Instruments (SMI) with an angular resolution of less than $0.5^{\circ}$ was used to record participants' eye movements. This infrared camera was placed under the 21-inch screen of the stimulus PC (screen resolution $1024 \times 768$ pixels), which was set up in a "recording room". An adjustable forehead rest was placed in front of the screen, so that the participant's eyes were positioned at a distance of approximately $70 \mathrm{~cm}$ from the centre of the screen. On a PC in an adjoining 'observation room', iView software (SMI) operated the camera and the calibration of the eye-tracking system. An extra mouse, keyboard and monitor were connected to the stimulus PC and located in the 
observation room. This enabled the experimenter to perform the necessary actions on the stimulus PC when calibrating the system from the observation room. GazeTracker $^{\mathrm{TM}}$ software (Lankford, 2000) ran on the stimulus PC to register participants' eye movements and their mouse-clicks. The 'recording room' was visible from the 'observation room' through a one-way screen and microphones enabled verbal communication between both rooms.

\subsection{Procedure}

The experiment was run in individual sessions of approximately 45-55 minutes. Because there were still some within-group prior knowledge differences (i.e., they had different general knowledge about the biology domain), participants in the HPK conditions first received the Training task (10 min), which allowed them to build a mental model of a virus's multiplication cycle (this was done to reduce possible large variability in prior knowledge within the HPK group). The HPK participants were instructed to answer the pretest using their knowledge acquired during the Training task because the virus of the pretraing task was a retrovirus as the HIV. Then, they completed the pretest. Participants in the LPK conditions started with the pretest (10 min.). All participants were informed of how to navigate through the system before the Learning task. After completing the pretest, all participants studied the Learning task (20 min), but before starting on this task, the eye-tracking system was calibrated. Participants' eye movements were recorded during the first three minutes of working on the Learning task; during this period of time they had to use a forehead rest. After this period of time, the eye-tracking camera was switched off, and participants could remove the forehead rest, but the GazeTracker ${ }^{\mathrm{TM}}$ software kept running to continue to $\log$ the mouse clicks (navigation data). Participants were not allowed to take notes during the Learning task. After completing the Learning task, 
participants rated the mental effort they had invested in studying the task, the mental effort they had invested to understand the concept map, and their disorientation. Participants were required to fill in each rating scale and could not continue to the next item unless they had done so; also they were not allowed to correct previous ratings. Finally, participants completed the posttest $(10 \mathrm{~min})$, after which they rated the mental effort they had invested in responding to the posttest.

\subsection{Data analysis}

\subsubsection{Navigation behaviour}

Navigation behaviour could be assessed through the GazeTracker ${ }^{\mathrm{TM}}$ logging files, because GazeTracker ${ }^{\mathrm{TM}}$ logged not only eye-movement data but also mouseclick data per node (or window) because clicks were required in order to open windows and return to the concept map. Therefore, were recorded the reading time of the concept map, the number of selections of each node, and also the reading sequence (i.e., the order of the nodes selection) for each participant.

\subsubsection{Eye tracking}

We used a dispersion-based method of fixation identification (Salvucci, 1999), and identified fixation points by a minimum number of 3 gaze points that fell within a certain dispersion, that is, were grouped within a radius of 40 pixels, and together had a minimal duration of $200 \mathrm{~ms}$. (This method is preferred for stimuli that are mainly pictorial.) Using GazeTracker ${ }^{\mathrm{TM}}$ the fixation data were exported to Microsoft Excel. This resulted in an overview of the coordinates and duration of each fixation, and (when applied) the LookZone or Area of Interest in which a fixation fell. There was also "summary" data like the number of fixations and mean fixation duration; when LookZones were applied, these "summary" data were also provided for each LookZone. Each node in the concept map, with some of the space around it, was 
identified as a LookZone. Therefore, there were LookZones on anatomic information nodes and macro-information nodes.

\subsubsection{Viewing behaviour}

To study viewing behaviour, analyses were conducted on the percentage of the total time participants had spent fixating on LookZones that corresponded to the 11 anatomic information nodes (i.e., constitutive elements of the host cell and the virus) and the LookZones that corresponded to the 5 macro-information nodes provided at the second level of the hierarchy (i.e., cell, virus, entrance of the virus, construction of the elements and departure of the viruses). The percentage of time spent fixating on the anatomic information nodes is an indication of the attention allocated to information required to understand the material, whereas the percentage of time spent fixating the on macro-information nodes is an indication of the attention allocated to the main categories of the document.

\section{Results}

Because of the small number of participants per condition, nonparametric tests were used to analyse the data, with the significance level set at .05. To test the effects of concept-map structure as a function of the level of prior knowledge, Mann Whitney tests were computed within each prior knowledge level and the significance level was divided by two to avoid type I error (i.e., the value of the significance level was set at .025).

Analysis of the pretest scores confirmed the prior knowledge differences: As one would expect, pretest factual knowledge scores were higher for the HPK participants $(\underline{\mathrm{M}}=6.75, \underline{\mathrm{SD}}=2.05)$ than for the LPK participants $(\underline{\mathrm{M}}=1.08, \underline{\mathrm{SD}}=$ 1.62), $\underline{\mathrm{U}}(12,12)=3, \underline{\mathrm{p}}<.001$, and so were the conceptual knowledge scores $(\underline{\mathrm{M}}=$ 7.92, $\underline{\mathrm{SD}}=2.57)$, than for the LPK participants $(\underline{\mathrm{M}}=0.92, \underline{\mathrm{SD}}=1.31), \underline{\mathrm{U}}(12,12)=0$, 
$\mathrm{p}<.001$. The answer "I do not know" represented $88.54 \%$ of the LPK participants' answers and only $27.86 \%$ of the HPK participants' answers. (For descriptives see Table 1.)

Insert Table 1 about here

\subsection{Learning outcomes}

Table 1 shows the descriptive statistics of the pre- to posttest knowledge gains, mental effort invested in the posttest, and mean response time in the posttest for the factual knowledge and conceptual knowledge.

\subsubsection{Pre- to posttest knowledge gains}

With respect to the effect of prior knowledge, the LPK participants gained more factual knowledge $(\underline{\mathrm{M}}=7.17, \underline{\mathrm{SD}}=1.80)$ than the HPK participants $(\underline{\mathrm{M}}=4.08$, $\underline{\mathrm{SD}}=2.68), \underline{\mathrm{U}}(12,12)=22.5 ; \underline{\mathrm{p}}=.002$; the LPK participants also gained more conceptual knowledge $(\underline{\mathrm{M}}=5.58, \underline{\mathrm{SD}}=2.11)$ than the HPK participants $(\underline{\mathrm{M}}=2.17$, $\underline{\mathrm{SD}}=3.79), \underline{\mathrm{U}}(12,12)=34, \underline{\mathrm{p}}=.014$.

With respect to the effect of concept-map structure, no effect of concept-map structure was found for the LPK participants in the case of factual knowledge, U(6, 6) $=17.5, \underline{p}=.467$; however, a beneficial effect of the HS, compared to NS, was found for the LPK participants in the case of conceptual knowledge, $\underline{U}(6,6)=7, \underline{p}=.036$. In the case of HPK participants, the HS led to higher factual knowledge gains than the $\mathrm{NS}, \underline{\mathrm{U}}(6,6)=4.5, \underline{\mathrm{p}}=.015$; for conceptual knowledge no effects of concept-map structure were found for the HPK participants, $\underline{\mathrm{U}}(6,6)=14.5, \underline{p}=.235$;

\subsubsection{Mental effort invested in posttest}


The LPK participants reported more mental effort in answering factual knowledge statements $(\underline{\mathrm{M}}=6.00, \underline{\mathrm{SD}}=1.35)$ than the HPK participants $(\underline{\mathrm{M}}=5.00$, $\underline{\mathrm{SD}}=1.35), \underline{\mathrm{U}}(12,12)=40, \underline{\mathrm{p}}=.027$. The LPK participants also reported more mental effort in answering conceptual knowledge statements $(\underline{\mathrm{M}}=6.83, \underline{\mathrm{SD}}=0.94)$ than the HPK participants $(\underline{\mathrm{M}}=5.83, \underline{\mathrm{SD}}=1.34), \underline{\mathrm{U}}(12,12)=39, \underline{\mathrm{p}}=.025$.

The HS, compared to the NS, led to lower ratings of mental effort for the LPK participants on both factual knowledge, $\underline{\mathrm{U}}(6,6)=4, \underline{\mathrm{p}}=.008$, and conceptual knowledge statements (marginal effect), $\underline{U}(6,6)=7, \underline{p}=.032$; however, no effect of concept-map structure was found on the ratings of mental effort by the HPK participants: for factual knowledge statements, $\underline{\mathrm{U}}(12,12)=14, \underline{\mathrm{p}}=.254$; for conceptual knowledge statements, $\underline{\mathrm{U}}(6,6)=11.5, \underline{\mathrm{p}}=.142$.

\subsubsection{Time on posttest}

The analyses did not reveal any significant effect on the time spent responding to the factual or conceptual knowledge statements (all $\underline{p}$ values were $<.10$ ).

Insert Table 2 about here

\subsection{Learning process measures}

Table 2 shows the descriptives of the process measures: mental effort invested in the Learning task, mental effort invested in understanding the concept map, disorientation during the Learning task, mean duration of eye fixation during the first three minutes of the Learning task, the percentage of time fixating on anatomic and macro-information LookZones, number of opened anatomic and functional nodes, and total time spent reading the concept map.

\subsubsection{Mental effort invested in the Learning task}


In the case of the general item measuring mental effort invested in the Learning task, no significant differences were found between HPK and LPK participants and between HS and NS (all p values were $>.10$ ). In the case of the specific item of mental effort, namely mental effort required to understand the concept map, no difference was found between LPK and HPK participants, $\underline{\mathrm{U}}(12,12)=68.5$, $\mathrm{p}=.420$. However, HS was associated with lower rates of mental effort, compared to the NS, for both LPK participants, $\underline{\mathrm{U}}(6,6)=0, \underline{\mathrm{p}}=.002$, and HPK participants, $\mathrm{U}(6$, $6)=2, \underline{p}=.005$

\subsubsection{Disorientation}

No significant difference in disorientation between HPK and LPK participants was found, $\underline{\mathrm{U}}(12,12)=57.5, \underline{\mathrm{p}}=.200$. For the LPK participants, the HS led to less disorientation than the NS, $\underline{\mathrm{U}}(6,6)=2, \underline{\mathrm{p}}=.005$; no effect of concept-map structure was found for the HPK participants, $\underline{U}(6,6)=8, \underline{p}=.054$.

\subsubsection{Duration of fixation and viewing behaviour}

Because the calibrations failed for two participants (two participants of the high prior knowledge group in the hierarchical condition), they were removed from the analyses.

No significant difference in duration of fixations between LPK and HPK participants was found, $\underline{\mathrm{U}}(12,10)=38, \underline{\mathrm{p}}=.448$. The HS led to higher duration of fixations for the LPK participants, $\underline{\mathrm{U}}(6,6)=6, \underline{\mathrm{p}}=.027$, but not for the HPK participants, $\mathrm{U}(6,4)=9, \underline{\mathrm{p}}=.261$.

As regards the viewing behaviour, in the case of the NS, the mean percentage of time spent fixating on the 11 anatomic nodes was higher for the HPK participants than for the LPK participants, $\underline{\mathrm{U}}(6,6)=5, \underline{\mathrm{p}}=.019$; no difference between HPK and LPK participants was observed in the HS, $\underline{\mathrm{U}}(6,4)=10, \underline{p}=.335$. In the case of HS, 
the mean percentage of time spent fixating on macro-information nodes was higher for LPK participants than for the HPK participants, $\underline{\mathrm{U}}(6,4)=3, \underline{\mathrm{p}}=.028$; no difference was found in the NS, $\underline{\mathrm{U}}(6,6)=13, \underline{\mathrm{p}}=.212$.

\subsubsection{Navigation behaviour and time on Learning task}

All participants opened each node at least once. There were no differences between HPK and LPK participants nor between HS and NS in the number of nodes opened (all $\mathrm{p}>.10$ ). All participants except one spent on the Learning task the maximum allotted time (20 min).

The HS tended to induce a systematic reading path from left to right and from top to bottom: $42.65 \%$ of the jumps from one node to another node respected this systematic reading sequence in the HS, compared to only $9.69 \%$ in the NS. The LPK participants tended to open the nodes dealing with the anatomic nodes more often in the HS than in the NS (marginal effect), $\underline{U}(6,6)=6.5, \underline{p}=.033$, but no difference was found for the HPK participants, $\underline{\mathrm{U}}(6,6)=14.5, \underline{\mathrm{p}}=.280$. No effect of prior knowledge and concept-map structure was observed on the number of opened functional nodes $($ all $p>.10)$

The level of prior knowledge did not affect the time spent reading the concept map, $\underline{\mathrm{U}}(12,12)=61, \underline{p}=.263$. However, LPK participants tended to spend more time reading the HS than the NS (marginal effect), $\underline{\mathrm{U}}(6,6)=7, \underline{\mathrm{p}}=.039$, but no difference was found for the HPK participants, $\underline{\mathrm{U}}(6,6)=9, \underline{\mathrm{p}}=.075$.

\section{Discussion}

The results from the present exploratory study suggested in line with our expectations (Hypothesis 2d) that a HS supported high conceptual knowledge gains for low prior knowledge participants as compared to the NS. Also in line with our expectations (Hypothesis 2d), the mental effort invested by the low prior knowledge 
participants in the posttest was higher in the NS than in the HS for both factual and conceptual knowledge. In addition, the HS reduced disorientation for low prior knowledge participants and, thus the Hypothesis 2a was verified. The analyses of the eye movements revealed also shorter mean fixation duration in the case of NS, compared to HS, for the low prior knowledge participants. This unexpected result (Hypothesis 2c) is discussed below.

Contrary to our expectations (Hypothesis 3d), the HS also facilitated factual knowledge gains for high prior knowledge participants. However, as expected, no effect of concept-map structure was observed on the invested mental effort in the posttest (Hypothesis 3d), disorientation (Hypothesis 3a), mental effort in Learning task (Hypothesis 3b) and fixation duration data for the high prior knowledge participants (Hypothesis 3c).

Although the findings regarding the effects of concept-map structure seem consistent with an expected expertise reversal effect when looking at the disorientation (Hypothesis 3a) and mental effort data (Hypothesis 3b), the finding that high prior knowledge participants gained more factual knowledge from the HS is not. It might have been the case that their mental model was consistent with the HS, which allowed them to focus on the factual information. This explanation is supported by findings of Mannes (1987), whose results indicated that if prior knowledge is organized in a similar way as the target text, readers build a better representation in memory of the text microstructure. Hofman and van Oostendorp (1999) also showed that learners with high prior knowledge may focus more on the text microstructure because they have resources to process a concept map. This interpretation is particularly pertinent to the present study, because HPK participants had a training session that might have facilitated subsequent processing of factual knowledge. 
The eye tracking and navigation data provide more detailed insight into the findings. For the low prior knowledge participants, duration of fixation was higher in the HS, which may be due to the fact that they had more cognitive resources available for processing the concept map as indicated by the lower disorientation and mental effort ratings for concept-map processing in the hierarchical conditions. However, high prior knowledge participants also rated the HS as of little effort demanding to process; but because of their prior knowledge these participants were not disoriented in the NS and presumably had enough capacity left to process information in the NS, as the percentage of eye fixation time data in the network condition suggest. These data showed that high prior knowledge participants were more able than low prior knowledge participants to focus their attention on the prerequisite concepts (i.e., anatomic concepts) required for the understanding of the material (Hypothesis 3a).

In accordance with our expectations (Hypothesis $1 \mathrm{~b}$ ) the navigation behaviour showed that the HS induced a systematic reading pattern, which may have resulted to the lower investment of effort in understanding the HS. Although low prior knowledge participants gained more conceptual knowledge from the HS, they did not open more functional nodes in the HS than in the NS, but in contrast opened more anatomic nodes. Because the latter are prerequisites for understanding the functional nodes, this suggests that the HS helped the low prior knowledge participants to focus more on prerequisite information to understand the HIV infection process. Moreover, the analyses conducted on the percentages of fixation time on LookZones corroborated the prediction that the HS guided participants' attention towards the main concepts (Hypothesis 1a) when participants had low prior knowledge. Indeed, low prior knowledge participants allocated more attention to the concepts 
corresponding to the main categories (i.e. macrostructure) than high prior knowledge participants in the hierarchical condition.

\subsection{Measurement issues}

\subsubsection{Mental effort invested in the Learning task and in the posttest}

No effects were found on the general item that measured investment of mental effort in the Learning task; however, on the specific item regarding investment of mental effort in understanding the concept map, there were differences between the two types of concept-map structure. Although understanding the concept map (i.e., conceptual knowledge) was part of the Learning task, the Learning task comprised other processes as well. Therefore, the general item tapped different types of cognitive load evoked by different processes. This likely led to differences in the degree of contribution of each type of cognitive load to the overall score between the two types of concept-map structure, although the overall rating was the same. This is why it is important to consider mental effort ratings during learning in relation to learning outcomes (Paas \& Van Merriënboer, 1993).

Regarding learning outcomes, the measurement of mental effort invested in the posttest can provide more information about the quality of learning outcomes than relying on performance measures alone (Paas \& Van Merriënboer, 1993; Van Gog \& Paas, 2008). Although mental effort invested in the posttest was not affected by concept-map structure for the high prior knowledge participants, this was the case for low prior knowledge ones: After having learned with the HS, answering the posttest statements required less investment of effort in the posttest. The combination of the higher gain in conceptual knowledge for low prior knowledge learners studying with the HS suggests that the HS leads to more efficient learning in terms of quality of acquired schemata. 


\subsubsection{Mental effort and disorientation}

It can be argued that disorientation and mental effort investment in conceptmap processing are highly related in the sense that higher disorientation induced by a concept map would increase the investment of mental effort in processing this concept map. However, these are different constructs and our data show different results on disorientation and effort invested in concept-map processing for high prior knowledge participants. This finding strongly suggests that it is fruitful to measure both disorientation and mental effort, and not rely on one of these measures alone to draw conclusions about the other.

\subsubsection{Mental effort and fixation duration}

The present study indicated that although subjective ratings of mental effort and fixation duration are both considered measures of cognitive load, they seem to measure different aspects of this construct (see also Van Gog et al., 2005). Of course, measures of mental effort are subjective and overall measures, whereas fixation duration data are objective measures that were only collected during the first three minutes of the Learning task. Thus, the difference may be an artefact of measuring cognitive load associated with the whole versus part of the process, but it may also be the case that experiencing an overall lower mental effort allows one to allocate more cognitive capacity to processing information in the Learning task, thereby leading to higher fixation duration (e.g., for low prior knowledge learners, mental effort for concept-map processing was higher in the NS, but they had a higher mean fixation duration in the HS). Unfortunately, recording eye movement data during the whole task (20 min) was not possible here, because the system would need to be recalibrated every few minutes, which would seriously interfere with the learning process.

\subsection{Limitations}


First of all, the results of this study as well as the potential implications mentioned here should be interpreted cautiously, because this was an exploratory study with a small number of participants. Second, regarding replications of the findings, it should be noted that our sample consisted of adults, rather than students. Third, we provided a training to eliminate some within-group differences in prior knowledge in the high prior knowledge participants, because these differences might have affected the results. However, as one of the reviewers pointed out, the training might also have affected the results, by providing a contextual, temporary knowledge effect. Finally, the number of links drawn in the two concept maps was not equal, which might also have influenced navigation and comprehension.

\subsection{Future research}

Our equipment did not allow us to reliably record eye movements during the entire processing of the Learning task. However, technological developments are rapid and new eye trackers do enable recording of eye movements continuously during tasks of long duration. Data from an entire task would allow investigating how processing demands fluctuate in different phases of the learning process and how these patterns are related to overall perceived investment of mental effort.

In addition, it would be interesting to measure learners' goals and strategies (and where possible correlate these with navigation and eye movement data), using verbal reporting techniques such as thinking aloud (Ericsson \& Simon, 1993) or cued retrospective reporting based on a record of eye movements (which is more informative than un-cued retrospective reporting; Van Gog, Paas, Van Merriënboer, \& Witte, 2005).

\subsection{Concluding remark}


Despite its limitations, the present study suggests that combining different process measures, such as disorientation and cognitive load, and tracing the process in more detail using eye movement and navigation data can provide us with interesting information and a better understanding of the processes that cause effects on learning from hypertexts. Learning from hypertext involves making decisions on a pathway based on prior knowledge, on organisational cues of the hypertext structure, and on the nature of the Learning task. Here, we only manipulated concept-map structure, but the type of research described here, that is, studying prior knowledge effects using combinations of process measurement techniques, can be very fruitful for studying learning from hypertexts with multidimensional characteristics. In such multidimensional hypertexts, even more opportunities for disorientation and high cognitive load arise because learners are not obliged to return to a concept map, but can go on to deeper levels at each node/link. 
Appendix A. Examples of factual knowledge statements (FK) and conceptual knowledge statements (CK)

(FK) Inside the virus, the enzymes are positioned near the viral RNA (Correct answer: right)

(FK) Inside the virus, the genetic material of the virus is carried by DNA ( answer: wrong)

(FK) The gp proteins allow the virus to be attached to the cell, associating with the receptors ( $\underline{\text { Correct answer: right }})$

(FK) Inside the virus, the enzymes are positioned near the viral RNA (Correct answer: right)

(CK) Before the attachment of the virus to the cell, the capsid is surrounded by an envelope (Correct answer: right)

(CK) The envelope and the capsid of the new virus are assembled at the same time (Correct answer: right)

(CK) The viral RNA is coded in viral DNA in order to allow the virus to integrate its genetic information to the genetic information of the cell. (Correct answer: right) (CK) If a new IHV exemplar do not have envelope, it will be still able to infect a cell (Correct answer: right) 
Prior Knowledge and Concept-map Structure 30

\section{Appendix B. The disorientation items}

Your difficulty to understand the relations between the pages of the lesson was: ...

Your difficulty to know what next page to read was: ...

Your difficulty to know where you were in the lesson was: ...

Your difficulty to find previous read information was: ...

Your difficulty to be on the right path was: ...

These items were answered on a 9-point Likert-type response scale ranging from 1 (very very low) to 9 (very very high). 


\section{References}

Ahuja, J., \& Webster, J. (2001). Perceived disorientation: An examination of a new measure to assess web design effectiveness. Interacting with Computers, 14 , $15-29$.

Amadieu, F., \& Tricot, A. (2006). Utilisation d'un hypermédia et apprentissage: Deux activités concurrentes ou complémentaires? [Using hypermedia and learning: Two concurrent or complementary activities?]. Psychologie Française, 51, 523.

Amadieu, F., Tricot, A., \& Mariné, C. (in press). Prior knowledge in learning from a non-linear electronic document: Disorientation and coherence of the reading sequences. Computers in Human Behavior.

doi:10.1016/j.chb.2008.1012.1017.

Beatty, J. (1982). Task-evoked pupillary responses, processing load, and the structure of processing resources. Psychological Bulletin, 91, 276-292.

Calisir, F., \& Gurel, Z. (2003). Influence of text structure and prior knowledge of the learner on reading comprehension, browsing and perceived control. Computers in Human Behavior, 19, 135-145.

Charness, N., Reingold, E. M., Pomplun, M., \& Stampe, D. M. (2001). The perceptual aspect of skilled performance in chess: Evidence from eye movements. Memory and Cognition, 29, 1146-1152.

Chen, S. Y., Fan, J.-P., \& Macredie, R. D. (2006). Navigation in hypermedia learning systems: Experts vs. novices. Computers in Human Behavior, 22, 251-266.

Chen, C., \& Rada, R. (1996). Interacting with hypertext: A meta-analysis of experimental studies. Human-Computer Interaction, 11, 125-156. 
Conklin, J. (1987). Hypertext: An introduction and survey. IEEE computers, 20(9), 17-41.

Cress, U., \& Knabel, O. B. (2003). Previews in hypertexts: Effects on navigation and knowledge acquisition. Journal of Computer Assisted Learning, 19, 517-527.

Cronbach, L. J., \& Snow, R. E. (1977). Aptitudes and instructional methods: A handbook for research on interactions. New York: Irvington.

de Jong, T., \& van der Hulst, A. (2002). The effects of graphical overviews on knowledge acquisition in hypertext. Journal of Computer Assisted Learning, $18(2), 219-231$.

Dillon, A., \& Gabbard, R. (1998). Hypermedia as an educational technology: A review of the empirical literature on learner comprehension, control and style. Review of Educational Research, 68, 322-349.

Dillon, A., Mc Knight, C., \& Richardson, J. (1993). Space - The final chapter or why physical representation are not semantic intentions. In C. Mc Knight, A. Dillon, \& J. Richardson (Eds.), Hypertext: A psychological perspective (pp. 169-191). Chichester, England: Ellis Horwood.

Duchowski, A. T. (2003). Eye tracking methodology: Theory and practice. London: Springer.

Ericsson, K. A., \& Simon, H. A. (1993). Protocol analysis: Verbal reports as data (Rev. ed.). Cambridge, MA: MIT Press.

Fiderio, J. (1988). A grand vision. Byte, 13(10), 237-244.

Haider, H., \& Frensch, P. A. (1999). Eye movement during skill acquisition: More evidence for the information reduction hypothesis. Journal of Experimental Psychology: Learning, Memory and Cognition, 25, 172-190. 
Hofman, R., \& Van Oostendorp, H. (1999). Cognitive effects of a structural overview in a hypertext. British Journal of Educational Technology, 30(2), 129-140.

Millisecond Software LLC. (2005). Inquisit 2.0.51002 [Computer software]. Seattle, WA: Sean Draine.

Jacobson, M. J., \& Archodidou, A. (2000). The design of hypermedia tools for learning: Fostering conceptual change and transfer of complex scientific knowledge. The Journal of the Learning Sciences, 9, 149-199.

Jacobson, M. J., Maouri, C., Mishra, P., \& Kolar, C. (1996). Learning with hypertext learning environments: Theory, design, and research. Journal of Educational Multimedia and Hypermedia, 5, 239-281.

Jonassen, D. (1989). Mapping the structure of content in instructional systems technology. Educational Technology Research and Development, 29(4), 3643.

Kalyuga, S., Ayres, P., Chandler, P., \& Sweller, J. (2003). The expertise reversal effect. Educational Psychologist, 38, 23-31.

Lankford, C. (2000). GazeTrackerTM: Software designed to facilitate eye movement analysis. Proceedings of the Eye Tracking Research and Applications Symposium (pp. 51-55). New York: ACM Press.

Lohman, D. F. (1986). Predicting mathemathanic effects in the teaching of higherorder thinking skills. Educational Psychologist, 21, 191-208.

Mannes, S. M., \& Kintsch, W. (1987). Knowledge organization and text organization. Cognition and Instruction, 4(2), 91-115.

McNamara, D. S., \& Kintsch, W. (1996). Learning from text: Effects of prior knowledge and text coherence. Discourse Processes, 22, 247-288. 
McNamara, D. S., Kintsch, E., Songer, N. B., \& Kintsch, W. (1996). Are good texts always better? Interactions of text coherence, background knowledge, and levels of understanding in learning from text. Cognition and Instruction, 14, 143.

Mohageg, M. F. (1992). The influence of hypertext linking structures on the efficiency of information retrieval. Human Factors, 34, 351-367.

Naumann, A., Waniek, J., \& Krems, J. F. (2001). Knowledge acquisition, navigation, and eye movements from text and hypertext. In U.-D. Reips \& M. Bosnjak (Eds.), Dimensions of internet science (pp. 293-304). Lengerich, Germany: Pabst Science Publishers.

Niederhauser, D. S., Reynolds, R. E., Salmen, D. J., \& Skolmoski, P. (2000). The influence of cognitive load on learning from hypertext. Journal of Educational Computing Research, 23, 237-255.

Otter, M., \& Johnson, H. (2000). Lost in hyperspace: Metrics and mental models. Interacting with Computers, 13, 1-40.

Ozuru, Y., Dempsey, K., \& McNamara, D. S. (in press). Prior knowledge, reading skill, and text cohesion in the comprehension of science texts. Learning and Instruction, doi:10.1016/j.learninstruc.2008.1004.1003.

Paas, F. (1992). Training strategies for attaining transfer of problem-solving skill in statistics: A cognitive load approach. Journal of Educational Psychology, 84, 429-434.

Paas, F., Tuovinen, J., Tabbers, H., \& Van Gerven, P. W. M. (2003). Cognitive load measurement as a means to advance cognitive load theory. Educational Psychologist, 38, 63-71. 
Paas, F., \& Van Merriënboer, J. J. G. (1993). The efficiency of instructional conditions: An approach to combine mental effort and performance measures. Human Factors, 35, 737-743.

Patel, S. C., Drury, C. G., \& Shalin, V. L. (1998). Effectiveness of expert semantic knowledge as a navigational aid within hypertext. Behaviour and Information Technology, 17, 313-324.

Potelle, H., \& Rouet, J.-F. (2003). Effects of content representation and readers' prior knowledge on the comprehension of hypertext. Journal of Human-Computer Studies, 58, 327-345.

Rayner, K. (1998). Eye movements in reading and information processing: 20 years of research. Psychological Bulletin, 124, 372-422.

Salmeron, L., Cañas, J. J., Kintsch, W., \& Fajardo, I. (2005). Reading strategies and hypertext comprehension. Discourse Processes, 40(3), 171-191.

Scott, B. M., \& Schwartz, N. H. (2007). Navigational spatial displays: The role of metacognition as cognitive load. Learning and Instruction, 17, 89-105.

Seufert, T. (2003). Supporting coherence formation in learning from multiple representations. Learning and Instruction, 13, 227-237.

Seufert, T., Schützea, M., \& Brünkena, R. (in press). Memory characteristics and modality in multimedia learning: An aptitude-treatment-interaction study Learning and Instruction, doi:10.1016/j.learninstruc.2008.1001.1002.

Shapiro, A. M. (1999). The relationship between prior knowledge and interactive overviews during hypermedia-aided learning. Journal of Educational Computing Research, 20, 143-167. 
Shapiro, A., \& Niederhauser, D. (2004). Learning from hypertext: Research issues and findings. In D. H. Jonassen (Ed.), Handbook of research on educational communications and technology (pp. 605-620). Mahwah, NJ: Erlbaum.

Shlechter, T. M. (1993). Computer-based instruction and the practical aspects of memory. Applied Cognitive Psychology, 7, 653-664.

Snow, R. E. (1989). Aptitude-treatment interaction as a framework for research on individual differences in learning. In P. L. Ackerman, R. J. Sternberg, \& R. Glaser (Eds.), Learning and individual differences. Advances in theory and research (pp. 13-59). New York: Freeman.

Stelmach, L. B., Campsall, J. M., \& Herdman, C. M. (1997). Attentional and ocular movements. Journal of Experimental Psychology: Human Perception and Performance, 23, 823-844.

Sweller, J. (1988). Cognitive load during problem solving: Effects on learning. Cognitive Science, 12, 257-285.

Sweller, J., Van Merriënboer, J. J. G., \& Paas, F. (1998). Cognitive architecture and instructional design. Educational Psychology Review, 10, 251-296.

Underwood, G., Chapman, P., Brocklehurst, N., Underwood, J., \& Crundall, D. (2003). Visual attention while driving: Sequences of eye fixations made by experienced and novice drivers. Ergonomics, 46, 629-646.

Underwood, G., Jebbett, L., \& Roberts, K. (2004). Inspecting pictures for information to verify a sentence: Eye movements in general encoding and in focused search. The Quarterly Journal of Experimental Psychology, 57, 165-182.

Van Gerven, P. W. M., Paas, F., Van Merriënboer, J. J. G., \& Schmidt, H. (2004). Memory load and the cognitive pupillary response in aging. Psychophysiology, 41, 167-174. 
Van Gog, T., \& Paas, F. (2008). Instructional efficiency: Revisiting the original construct in educational research. Educational Psychologist, 43, 16-26.

Van Gog, T., Paas, F., \& Van Merriënboer, J. J. G. (2008). Effects of studying sequences of process-oriented and product-oriented worked examples on troubleshooting transfer efficiency. Learning and Instruction, 18, 211-222.

Van Gog, T., Paas, F., \& Van Merriënboer, J. J. G. (2005). Uncovering expertiserelated differences in troubleshooting performance: Combining eye movement and concurrent verbal protocol data. Applied Cognitive Psychology, 19, $205-$ 221.

Van Gog, T., Paas, F., Van Merriënboer, J. J. G., \& Witte, P. (2005). Uncovering the problem-solving process: Cued retrospective reporting versus concurrent and retrospective reporting. Journal of Experimental Psychology: Applied, 11, 237-244. 
Prior Knowledge and Concept-map Structure 38

Table 1.

High and low prior knowledge participants' means (and SD) of pre- to posttest knowledge gain, mental effort and response time scores as a function of type concept-map structure

\begin{tabular}{|c|c|c|c|c|}
\hline & \multicolumn{2}{|c|}{ Low prior knowledge } & \multicolumn{2}{|c|}{ High prior knowledge } \\
\hline & $\mathrm{NS}$ & $\mathrm{HS}$ & $\mathrm{NS}$ & $\mathrm{HS}$ \\
\hline & $\underline{\mathrm{M}}(\underline{\mathrm{SD}})$ & $\underline{\mathrm{M}}(\underline{\mathrm{SD}})$ & $\underline{\mathrm{M}}(\underline{\mathrm{SD}})$ & $\underline{\mathrm{M}}(\underline{\mathrm{SD}})$ \\
\hline \multicolumn{5}{|c|}{ Factual knowledge } \\
\hline Pretest & $0.83(1.33)$ & $1.33(1.97)$ & $6.67(2.07)$ & $6.83(2.23)$ \\
\hline Posttest & $8.00(2.83)$ & $8.50(1.64)$ & $9.17(1.94)$ & $12.50(2.35)$ \\
\hline Knowledge gain & $7.17(1.94)$ & $7.17(1.83)$ & $2.50(2.66)$ & $5.67(1.63)$ \\
\hline Mental effort & $6.83(0.75)$ & $5.17(1.33)$ & $5.33(1.21)$ & $4.67(1.51)$ \\
\hline Time on posttest (ms) & $7587(2793)$ & $6943(1778)$ & $7019(2657)$ & $6248(956)$ \\
\hline \multicolumn{5}{|c|}{ Conceptual knowledge } \\
\hline Pretest & $1.00(1.55)$ & $0.83(1.17)$ & $7.00(2.37)$ & $8.83(2.64)$ \\
\hline Posttest & $5.50(1.52)$ & $7.50(1.38)$ & $8.33(2.58)$ & $11.83(1.94)$ \\
\hline Knowledge gain & $4.50(1.52)$ & $6.67(2.16)$ & $1.33(3.78)$ & $3.00(3.95)$ \\
\hline Mental effort & $7.33(0.82)$ & $6.33(0.82)$ & $6.17(1.33)$ & $5.50(1.38)$ \\
\hline Time on posttest (ms) & $8661(2759)$ & $7965(2338)$ & $7975(2280)$ & $8431(2574)$ \\
\hline
\end{tabular}

NS: Network concept-map structure; HS: Hierarchical concept-map structure. 
Table 2.

High and low prior knowledge participants' means (and $\underline{\mathrm{SD}}$ ) of learning process measures as a function of type of concept-map structure

\begin{tabular}{lllll}
\hline & \multicolumn{2}{c}{ Low prior knowledge } & \multicolumn{2}{c}{ High prior knowledge } \\
\cline { 2 - 5 } & $\mathrm{NS}$ & $\mathrm{HS}$ & $\mathrm{NS}$ & $\mathrm{HS}$ \\
\cline { 2 - 5 } & $\underline{\mathrm{M}}(\underline{\mathrm{SD}})$ & $\underline{\mathrm{M}}(\underline{\mathrm{SD}})$ & $\underline{\mathrm{M}}(\underline{\mathrm{SD}})$ & $\underline{\mathrm{M}}(\underline{\mathrm{SD}})$ \\
\hline Mental effort (general item) & $6.67(1.63)$ & $5.67(1.37)$ & $6.00(1.67)$ & $5.83(1.33)$ \\
Mental effort (specific item) & $6.50(1.52)$ & $2.00(1.26)$ & $6.17(1.47)$ & $2.67(1.63)$ \\
$\begin{array}{l}\text { Disorientation } \\
\text { Mean duration of fixation (ms) }\end{array}$ & $5.87(1.29)$ & $3.00(1.48)$ & $4.47(1.87)$ & $2.87(0.94)$ \\
\% of fixation time in anatomic & $395(52)$ & $441(34)$ & $414(33)$ & $407(16)$ \\
& & & & \\
LookZones & $41.43(8.15)$ & $48.19(9.00)$ & $53.52(9.27)$ & $53.75(14.45)$ \\
\% of fixation time in macro- & $25.15(6.37)$ & $40.46(8.98)$ & $24.41(9.28)$ & $29.73(3.94)$ \\
& & & & \\
information LookZones & & & & \\
Opened anatomic nodes & & & & \\
Opened functional nodes & $23.83(5.67)$ & $31.00(6.48)$ & $22.00(0.63)$ & $25.16(5.00)$ \\
Time on concept-map reading task & $26.83(6.85)$ & $30.83(10.25)$ & $29.50(4.88)$ & $34.83(10.88)$ \\
\hline
\end{tabular}


Prior Knowledge and Concept-map Structure 40

Figure Captions

Figure 1a. Hierarchical concept-map structure.

Figure 1b. Network concept-map structure. 
Prior Knowledge and Concept-map Structure 41
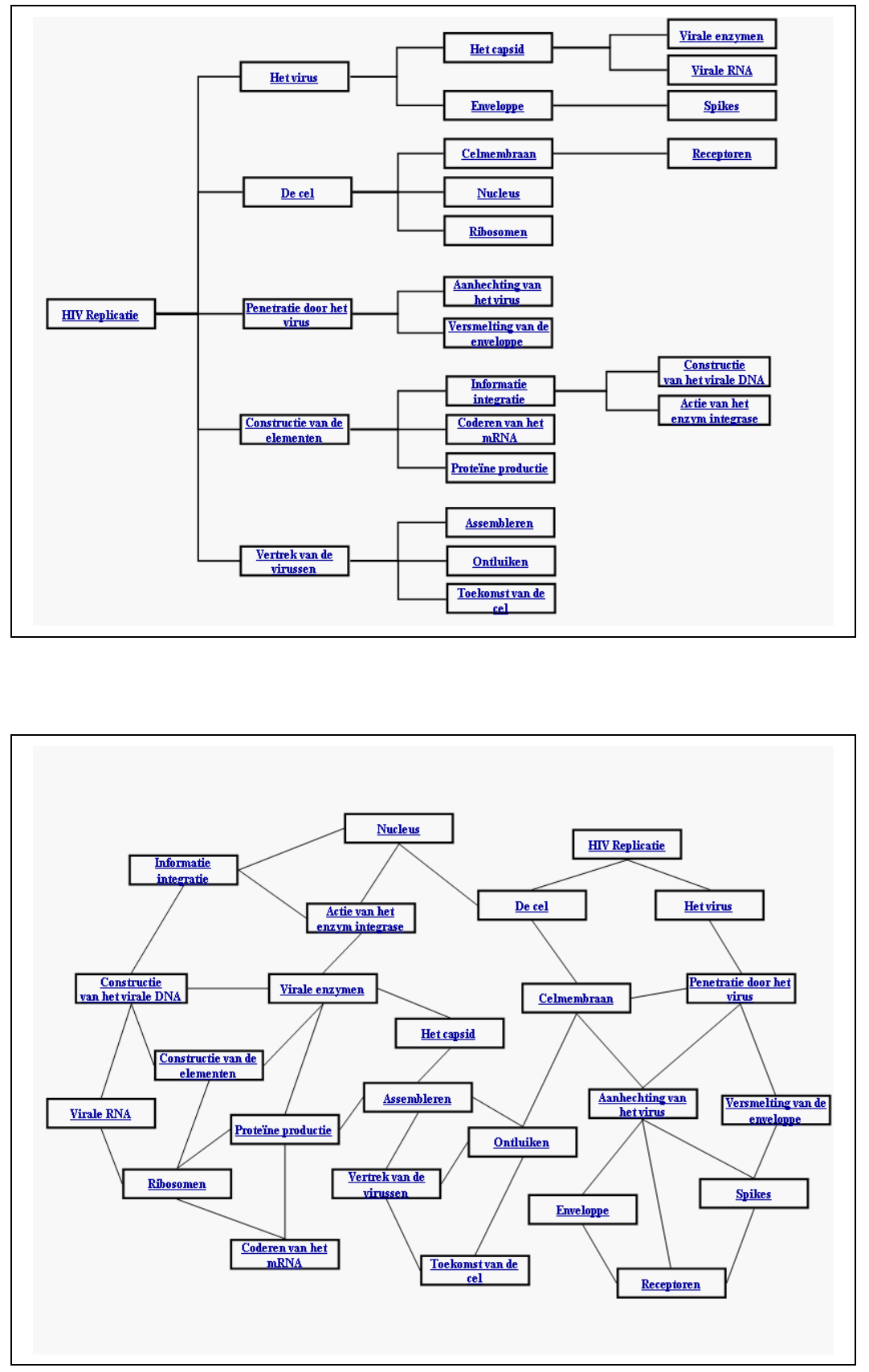